\title{
Transcending false dichotomies and diagnostic silos to reduce disease burden in mental disorders
}

\author{
Patrick D. McGorry ${ }^{1,2}$ (D) Barnaby Nelson ${ }^{1,2} \cdot$ Stephen J. Wood ${ }^{1,2,3} \cdot$ Jai L. Shah ${ }^{4,5,6} \cdot$ Ashok Malla $^{4,5,6} \cdot$ Alison Yung $^{1,2,7}$
}

Received: 24 September 2019 / Accepted: 30 June 2020 / Published online: 18 July 2020

○) Springer-Verlag GmbH Germany, part of Springer Nature 2020

\section{Introduction}

The at-risk mental state (ARMS) strategy for psychosis, although highly influential, remains contested, with recent critiques suggesting that it should be replaced with a public health/primary prevention approach. Implicit in these is a pessimistic stance towards treatment, constrained by the tenacious bias of the "soft bigotry of low expectations", which denies or discounts the positive evidence base that now exists. We argue that this is a classic example of the self-defeating false dichotomies and binary thinking that have impeded progress in psychiatry. In this commentary, we contend that secondary and tertiary prevention efforts have a crucial role in reducing disease burden through prevalence reduction and disease modification, and in no way conflict with the holy grail of primary prevention. We regard a preventive or public health strategy as essential for all stages of mental illness, just as it is in other non-communicable diseases (NCDs). We see the ARMS concept, as a prototype and gateway for the clinical staging model which represents

Patrick D. McGorry

pat.mcgorry@orygen.org.au

1 Orygen, 35 Poplar Rd (Locked Bag 10), Parkville, VIC 3052, Australia

2 Centre for Youth Mental Health, The University of Melbourne, Parkville, Australia

3 School of Psychology, University of Birmingham, Birmingham, UK

4 Department of Psychiatry, McGill University, Montreal, Canada

5 Prevention and Early Intervention Program for Psychosis (PEPP), Douglas Mental Health University Institute, Montreal, Canada

6 ACCESS Open Minds, Douglas Mental Health University Institute, Montreal, Canada

7 School of Health Sciences, University of Manchester, Oxford Rd, Manchester M13 9PL, UK the basis for a viable public health strategy with the goal of reducing incidence, prevalence, and disease impact for not only psychotic disorders, but across the full spectrum of mental and substance use disorders.

\section{Beyond binary}

Prevention and treatment in mental disorders have the same end goal as in physical illness, namely the reduction of disease burden and improvement of quality of life, personal wellbeing and productivity. However, psychiatry constantly falls into the trap of setting up false dichotomies and is plagued by binary thinking which the other major NCDs seem to have transcended. The most fundamental example is the mind-body split, which creates constant tension between biological and psychosocial perspectives on mental illness. Earlier critiques of early intervention for psychosis pitted it against treatment for chronic schizophrenia e.g., Castle [1], and more recently a series of critiques and metanalyses of the ARMS strategy perpetuate this conceptual error. The latter prompted us to extend our previous views [2] and reflect on the range of opportunities that a non-binary perspective creates to reduce disease burden not only in psychosis but transdiagnostically.

A provocative recent editorial by Ajnakina et al. [3] questioned the value of the ARMS for psychosis concept and the first generation of strategies - the ultra-high risk (UHR) or ARMS clinic. This follows other recent critiques that have questioned the value of the ARMS approach from a public health perspective $[4,5]$. The critique by Ajnakina et al. was justified by the authors to marshal support for what they term the "public health approach," by which they meant primary prevention. This 'either-or' approach, in which primary, secondary and tertiary preventive interventions are somehow placed in competition with one another, can be seen as a marker of the immaturity of our field in contrast to other major NCDs. We argue that false dichotomies and 
binary thinking of this type might attract attention and fan the flames of debate, but they dissipate the creative energy of our field and actually hamper progress. In cancer, diabetes and cardiovascular disease (CVD), for example, we see balanced efforts to reduce incidence, to diagnose and treat at the earliest clinical stage, to increase survival and quality of life for established illness, and to offer humane palliative care. Here genuine debate centers on the optimal balance of risk and benefit at each stage of illness, rather than whether we should privilege one particular stage over others.

\section{Public health, prevention and disease modification: a global opportunity}

A public health approach-defined as "the science and art of preventing disease, prolonging life and promoting health" [6] - applies across all stages of illness, not merely to the general population or to asymptomatic high risk groups. It allows risk and protective factors to be identified at each stage of illness for onset, progression, remission or recovery. Clinical staging enables such a preventive or public health approach to be applied at every stage of mental disorders, with the goal of reducing incidence, prevalence and disease impact and severity. Prevention is of course better than cure, but it is contingent on a clear understanding of causes and mechanisms leading to disease onset. While we have a relatively robust knowledge of an array of risk factors in multiple genetic, social and personal domains, relying entirely on eliminating the latter would be irresponsible given the lack of understanding of mechanisms underlying the conversion of risk factors to disease states. Prevalence reduction and disease modification are also crucial in reducing disease burden, and people developing, or grappling with, these illnesses should be given the best chance not only of cure but at least a fulfilling and long life too.

Momentum for an inclusive approach is building. The World Economic Forum (WEF) in 2011 identified mental illness as the number one health issue reducing global gross domestic product (GDP) [7]. In Davos in January 2019, the WEF proceeded to make mental health a major priority in its annual program. Mental illness also represents the lowest hanging fruit in terms of capacity to impact because implementation failure for effective treatments and the treatment gap are by far the highest in the whole of global health care [8]. Encouragingly, the United Nations has begun to include preventive mental health targets in its Sustainable Development Goals (SDGs) and a social movement, the Movement for Global Mental Health, is increasingly active. Stigma is reducing slowly, but progressively, in many highincome countries. The time has never been more opportune to conceive and implement a preventive psychiatry which transcends false dichotomies, spans all stages of illness, and which has the common goal of reducing the burden not only of psychotic illnesses but of all mental and substance use disorders.

\section{Reducing the burden of disease}

Disease burden can be reduced by reducing incidence, prevalence and/or severity. Each of these targets requires a preventive approach framed within a population health or public health context. In the 1990s, Mrazek and Haggerty [9] influentially redefined preventive strategies in mental health with a new framework which superseded the standard primary, secondary and tertiary prevention concepts. Primary prevention was split into universal and selective strategies depending on the population being targeted. The version of a public health approach as described by Ajnakina et al. [3] has constrained it to these primary (universal and selective) forms of prevention, both of which aim to reduce the incidence of disease in asymptomatic people with a variable level of intrinsic risk. Indicated prevention, in which early clinical features are co-opted as indicators of risk for fully fledged disorder, sits in a no-man's land, and while it was a conceptual change that supported the ARMS paradigm shift, its ambiguous status located between primary and secondary prevention has created subsequent confusion and fuelled controversy.

One practical solution to this ambiguity is to regard indicated prevention as focusing upon the earliest clinical stage, where a need for care is present [10]. Indicated prevention is best seen as a prevalence reducing/disease modifying strategy and therefore constitutes early secondary prevention, although some US early psychosis researchers have sought to characterise it as reducing incidence of full threshold disorder in sub-threshold cases [11]. That stance played into the hands of critics who sought to misrepresent the strategy as harming people through overtreatment of those who were "normal" and merely at risk [12]. However, people in this so-called "sub-threshold" stage have a demonstrable need for care [13, 14]. Many do seek help, not only for sub-threshold psychotic symptoms but for general distress, and other symptom clusters, notably anxiety and depression along with substantial functional impairment. We therefore regard it as the first clinical stage where they have demonstrated a need for, and measurable benefit from, health care. This still represents a preventive strategy, since a minority of cases progress to Stage 2 or fully-fledged psychotic disorder, and it is possible to reduce the risks of this progression at least for one to two years [2,15-19]. Incidentally, this is also true for first episode psychosis (FEP) and even beyond into the "critical period" of the first 5 years of illness, where the risk progression to prolonged schizophrenia or other persistent 
psychotic disorders can be reduced [20-22], even though it is then usually described unequivocally as treatment. This underlines the fact that a preventive or "public health" approach is not just viable but in fact essential at all stages of illness. Primary prevention (universal and selective) reduces incidence, secondary prevention (indicated prevention, early diagnosis and relapse prevention) reduces prevalence, and tertiary prevention (recovery programs, rehabilitation and targeting treatment resistance) reduces severity and modifies disease impact, and collectively they all help to reduce the burden of disease. Below we describe clinical staging as a public health model which transcends these false dichotomies [10].

Universal and selective prevention strategies targeting risk factors, as in cardiovascular disease and cancer, have been effective for incidence reduction. However, intervention at the earliest recognisable stage (which can be asymptomatic, e.g., hypertension, prediabetes, or characterised by mild clinical features) is also placed at a premium to reduce impact, progression of illness, and burden. The global experience and the wealth of data generated from the heuristic and prototypical development of the ARMS/UHR concept in psychosis has produced many benefits. It led us to adapt and reformulate the clinical staging model from general medicine, and to articulate the relative value and purpose of these interventions $[10,23]$. In this context, the goal of ARMS services can be characterised as the equivalent of inserting stents in patients with warning signs such as chest pain, before myocardial infarction occurs, or removing carcinoma-in situ in breast or cervical cancer before extension of disease can occur. Thus, while its full potential may not have been realised in practice, it sits comfortably within a modern public health approach. It is reasonable to question the way this strategy has been implemented in psychiatry so far, and to wonder if there is a better way of achieving these goals, but to set out to comprehensively devalue the contribution of the strategy and the positive effect it has had on research and practice is regrettable [2].

In incidence reduction, the feasibility of tackling the modest number of risk factors on offer and track record of efforts to date are issues that have to be addressed. The ARMS approach has been criticised in large part for a perceived failure to have widespread impact $[3,5]$. Primary prevention of psychosis (and indeed all mental disorders) targeting the range of significant but individually modest risk factors (childhood adversity, urban birth and upbringing, and especially cannabis use) is even more vulnerable to such pessimism, especially on feasibility grounds, but the endeavour certainly should not be abandoned. Yet we can be much more confident that aggressive action to reduce prevalence at all clinical stages, from the earliest and continuing right through to the late stages of illness, is an approach which, if designed and funded in proportion to need and present evidence, would result in a substantial reduction of disease burden much sooner.

\section{Value, limitations and future of the ARMS concept}

In the wake of other recent critiques [4, 5], we have elsewhere reflected on the value and limitations of the ARMS/ UHR concept [2, 24-26]. While it is of proven worth in itself, the concept has much wider potential value and we see it as a crucial platform to building something much more transformational.

\section{Biological markers}

The argument that ARMS studies have not yielded specific biological markers of psychosis as reflecting a failure of the ARMS service model and research strategy is misguided. First, identifying biomarkers was only one aspect of the predictive ambitions of the ARMS approach, which in fact was always intended to have a broader biopsychosocial target. Clinically important psychosocial predictors of outcome have been identified in this population. For example, high levels of distress, low self-esteem, high suicidality, poor social support, and history of childhood maltreatment are all markers of both personal suffering and indicators of poor outcome [27-29]. Second, some biological markers have predictive value for transition to psychosis, albeit very modest so far, and neurobiological aspects of early psychosis, including the prodrome and first episode, have been one of the most active areas of biological research into psychosis over the last several decades. The early psychosis clinical population is considered invaluable for making further progress on the integration of neurobiological and genetic data, where the small risk associated with various biomarkers is a poor guide to their biological importance [30]. Third, the limited utility of biological makers of mental illness is widely recognised as a problem for biological psychiatry generally, across disorders (a problem, in part, of monocausal thinking [31]), and should certainly not be seen as a problem that is somehow unique to ARMS research studies.

\section{Intervention}

Another weakness of the recent critiques is a basic misreading of the evidence, especially on interventions. Systematic reviews and meta-analyses are powerful and influential tools. However, if the question they seek to address is poorly formulated or the methods used are inappropriate [32], the wrong interpretation can be drawn. An unfortunate example of both errors is the recent network meta-analysis of Davies and colleagues $[33,34]$. These researchers compared 
the relative effectiveness of experimental interventions in the UHR group against each other and to a heterogeneous group of "control" conditions, many of which contained active treatments, and found that while a range of treatments were effective in reducing the risk of transition to psychosis, reducing symptoms and promoting functional recovery, no one intervention was superior to another, although most studies included a psychosocial (usually CBT based) component. It is common in health care for different treatments, targeting different mechanisms, to achieve similar results. We see this in hypertension and in depression [35, 36]. Treatment selection is then based on safety concerns and patient preference-without leading to questioning the value of demonstrably effective treatments. However, in focusing on a question of second order importance and strongly suggesting the lack of superiority of any one intervention was problematic, Davies et al. have created a false perception that treatments are not effective for this group. This is despite a number of meta-analyses clearly showing that it is possible to delay transition by $24-48$ months at least, with a $50 \%$ risk reduction [16, 17, 19, 37]. In recent trials, transition rates in both active and control groups are comparatively low $(8-11 \%)$, which may be partly due to the efficacy of the "background" psychosocial intervention provided in all treatment arms [38], and symptomatic and functional outcomes are variable but favourable at longer term follow up and better than at baseline [39]. These results are produced through largely transdiagnostic and variable psychosocial interventions. Hence, some of the pessimism we see in the critiques is manufactured from muddled and pessimistic thinking. Our field should be encouraged that, thanks to the ARMS/UHR concept and the multiple RCTs that have now been completed, it is now possible to delay psychosis onset just as the diabetes field has been encouraged that this is now possible in type 1 diabetes [40]. The next stage of research needs to establish the correct sequence for interventions and personalise treatment [2].

\section{Pathways to care}

Recent critiques $[3,5]$ rely heavily on data from a single ARMS clinic or at least from a single geographical area (South London) [41]. However, the issue of pathways to care for FEP is likely dependent on the system of care and many other local factors and, hence, needs to be examined more broadly and across settings. Even compared only with our data from the Northwestern region of Melbourne (the Orygen catchment area), 20\% of FEP patients seen in the first episode clinic come via the ARMS clinic or other Orygen clinics, a rate substantially higher than the 4.1 and 5.19\% reported in South London [41, 42]. This higher rate indicates that the utility of ARMS clinics in identifying and providing clinical services to people on the path to FEP is also a function of efficient identification. They are also important for improving clinical outcomes, as the outcomes of FEP patients who have previously been seen at ARMS clinics have been found to be superior to FEP patients who entered FEP services directly [43], although a subgroup may be treatment resistant [44]. The latter can potentially be identified as such much earlier. The London data may, therefore, be more of an outlier than the norm, an issue which perhaps requires further examination. Other possible explanations are that the identification approaches used in the South London ARMS clinic may not be functioning well, with poor reach of services and problems with the referral and help-seeking pathways for those with emerging psychotic symptoms. A more optimistic perspective is that the South London ARMS clinic may in fact be relatively effective in preventing or substantially delaying onset of FEP (hence only a small proportion are referred on to FEP services). These possibilities need to be carefully considered rather than prematurely closing on the interpretation that ARMS clinics lack utility.

Nevertheless, the approach we have taken to identifying UHR patients has now been broadened beyond specialised ARMS clinics to include youth mental health enhanced primary care clinics (the headspace model, now being joined by other initiatives such as Jigsaw in Ireland and ACCESS Open Minds in Canada) [45-47]. In some cases, these broadspectrum integrated youth health services provide another much more accessible "soft entry" portal for identifying UHR cases as well as a broad spectrum of emerging mental ill-health, using a screening approach and then specialised ARMS assessment of those who screen positive [48]. This approach has been successful in recruiting to a major treatment trial in this clinical population [49], which recruited 342 participants using this pathway over a two-year period from four headspace centres in Melbourne. The statement by Ajnakina and colleagues [3] that headspace has not proven effective is not only untrue [50], but also irrelevant to whether it is a more efficient and wider channel for identifying UHR cases. Despite the wider portal introduced by broad youth mental health services, it is possible and even likely, due to the nature of emerging psychosis (suspiciousness, social isolation, etc.), that some patients will not naturally seek help during the ARMS phase. However, pathways to care research suggests that many or most cases in fact do [51-53], and health service structure and processes therefore need to be reformed and optimised to efficiently identify these cases, not give up on attempting to do so.

\section{Extending the ARMS criteria}

The UHR concept was never expected to be homotypic [54], though the US-led endeavour to have it included in the DSM 5 classification, in our view, did seek to imply this [11]. 
While the UHR criteria have a strong valence for full threshold psychosis [55, 56], they are also useful in identifying and predicting other syndromal and functional outcomes [57, 58]. A long term follow up study by our Melbourne group revealed that $70 \%$ of UHR patients who did not develop psychosis ("non-transitioned" cases) experienced persistent or newly incident non-psychotic disorders over a 2-14 year follow up period, mainly mood disorders (49\%) and anxiety disorders (35\%) [58]. These figures, as well as high rates of persistent attenuated psychotic symptoms, have been substantiated in a recent systematic review [59]. Conversely, other recent work has claimed that only a minority $(\sim 30 \%)$ of FEP cases do not pass through a previous stage of attenuated psychotic symptoms [60]. A related finding has been the fact that onset of FEP can emerge out of non-psychotic precursor states. Lee and colleagues [61] demonstrated that people at risk of non-psychotic disorders (identified through the presence of sub-threshold non-psychotic symptoms, such as depression and OCD) were at elevated risk of psychotic disorder (3.87\% 3-year incidence rate) —not as high as people meeting UHR criteria (24.63\% 3-year incidence rate), but substantially higher (77.4-fold) than the general population.

Finally, there is increased recognition that persistent attenuated psychotic symptoms, even if transition does not occur, represents a poor clinical outcome [59, 62]. For example, we recently showed that UHR patients who had persistent attenuated psychotic symptoms displayed poorer functioning and more severe general psychopathology and negative and depressive symptoms at follow up compared to those without persistent attenuated psychotic symptoms (a difference which was not present at baseline), and that persistent attenuated psychotic symptoms were associated with reduced grey matter volume [63]. We have also found that those who transition from a treated ARMS to FEP have fewer months of remission and higher rates of clozapine treatment compared to those who presented de novo to FEP services, suggesting that transitioning to FEP despite having received indicated interventions portends a potentially poorer prognosis [44]. Detecting these patients earlier, if they are indeed at risk not only of psychosis but of treatment resistance, could be of even greater value, if for example they were fast-tracked to treatment with clozapine.

These studies have all illuminated the nature and course of psychopathology, emphasising its heterotypic and pluripotent trajectories, beyond the silos of the DSM. Together, they indicate that while the UHR criteria do have greater valence for psychosis outcomes [64], they also have substantial valence for persistent or incident non-psychotic disorders $[63,65,66]$, that full-threshold psychosis may emerge out of risk states not characterised by attenuated psychotic symptoms [60, 61], and that persistent attenuated psychotic symptoms remain an important clinical target. There is also the opportunity to intervene early for treatment resistance should transition occur. These findings speak not only to the pluripotency of the UHR phenotype but also to the diffuse and non-specific symptom patterns of early stages of mental disorders generally [2]. A recent advance has been to operationally define these early clinical phenotypes that require intervention in their own right but also signal risk for evolving into more severe stages of disorder transdiagnostically. This composite definition has been referred to as the "Clinical High At Risk Mental State" (CHARMS) approach $[2,67]$. Although the target of this identification strategy is a first episode serious mental disorder broadly defined (Stage 2 mental disorder, see below), it also promises to maximise the identification of young people on the pathway to FEP by picking up on those who progress to FEP from non-UHR precursor states (Stage 1 non-psychotic symptoms). A more fluid approach to inclusion of Stage 1 cases [68] might turn out to be more feasible and effective.

\section{Clinical staging}

The clinical staging model in psychiatry, which we introduced to the field over a decade ago $[23,69,70]$, captures this pluripotent risk concept far better than traditional diagnostic manual-based approaches. This model, which parallels staging models in general medicine (e.g., cancer or kidney disease), moves beyond the traditional dichotomous approach to psychiatric diagnosis by defining the extent of disease progression based on severity, duration and course of symptoms. The model attempts to determine the position of an individual along a continuum of illness, with overlapping and pluripotent microphenotypes developing over time into particular (possibly comorbid) macrophenotypes $[23,69,70]$. The differentiation of early and milder clinical phenomena from more severe and chronic phenomena lies at the heart of the concept and allows the clinician to select appropriate treatments according to stage $[23,69,70]$. Interventions should be proportional to need and risk of extension of the clinical phenotype. The clinical staging approach puts emphasis on where a person sits in the evolution of disorder transdiagnostically (i.e. beyond traditional diagnostic categories). A mixture of psychiatric symptoms, which are sub-threshold for a range of traditional diagnostic categories, is a typical clinical presentation when young people first seek help [71]. In this way, the model moves outside the straitjacket (and arguably poor validity [72]) of current diagnostic boundaries, a move consistent with a general trend in contemporary psychiatry, e.g., the National Institute of Mental Health (NIMH), Research Domain Criteria (RDoC) [73, 74], and the Hierarchical Taxonomy of Psychopathology (HiTOP) [75] approach. The RDoC approach attempts to transcend DSM-defined diagnostic categories by basing 
psychiatric nosology on neuroscience and behavioural science [76]. It is a research framework and is not intended for clinical purposes at present. HiTOP provides a system for organizing psychopathology, offering a hierarchical dimensional approach to psychiatric classification [77]. Its clinical utility has been uncertain [78], however, recent attempts to address this have indicated the potential value of HiTOP although optimal cut-offs are needed to guide clinical decision making [79]. While the focus here is on clinical staging, the possibility of integrating these approaches to create a more complete model is of future interest.

\section{Implications for service reform and research strategy}

There is a manifest need to move beyond the silo-based thinking of traditional diagnostic approaches if we are to deliver early intervention in a way that works for people experiencing mental ill-health and reduces the impact and burden of potentially severe and disabling mental illnesses. Secondary and tertiary prevention efforts have a crucial role in reducing disease burden through prevalence reduction and disease modification, and in no way conflict with the holy grail of primary prevention. Hence, a preventive or public health strategy is essential for all stages of mental illness, just as it is in other NCDs. The narrow "public health" approach that Ajnakina et al. [3] advocate will not provide any greater relief to individuals with early symptoms, who currently often do not have access to the systems of care that they require, nor will it advance our understanding of disease onset and progression. A redesign of mental health care with a transdiagnostic low threshold/soft entry portal, in combination with targeting population level risk factors through policy and education strategies, to the extent that is understood and feasible, is a solution which deals with many of the issues these authors raise.

How to structure and sequence increasing specificity and expertise beyond entry remains a valid focus for the next generation of health services research $[10,80,81]$. The clinical staging model offers a viable public health strategy through its goal of reducing incidence, prevalence, and disease impact for not only psychotic disorders, but across all mental and substance use disorders. The clinical staging model has been developed to complement and integrate genuine syndromes such as mania, psychosis and depression with the onset and differentiating stages of illness, and to guide research and treatment. It is a sequel to the staged approach that was catalysed by the UHR concept and translated into reality through ARMS clinics. It encompasses and supports the primary prevention/public health approach cherished by critics. The next decade will show whether this inclusive approach can be validated or ideally improved upon.

Acknowledgements PDM is supported by a National Health and Medical Research Council (NHMRC) Senior Principal Research Fellowship (1155508). BN is supported by a NHMRC Senior Research Fellowship (1137687). JLS is supported by a clinician-scientist salary award from the Fonds de Recherche du Québec-Santé. AM is funded through the Canada Research Chairs Program. AY is supported by a NHMRC Principal Research Fellowship (1136829).

\section{Compliance with ethical standards}

Conflict of interest None to declare.

\section{References}

1. Castle DJ (2012) The truth, and nothing but the truth, about early intervention in psychosis. Aust N Z J Psychiatry 46(1):10 13. https://doi.org/10.1177/0004867411432553

2. McGorry PD, Hartmann JA, Spooner R, Nelson B (2018) Beyond the "at risk mental state" concept: transitioning to transdiagnostic psychiatry. World Psychiatry 17(2):133-142. https:// doi.org/10.1002/wps.20514

3. Ajnakina O, David AS, Murray RM (2019) 'At risk mental state' clinics for psychosis - an idea whose time has come — and gone! Psychol Med 49(4):529-534. https://doi.org/10.1017/S0033 291718003859

4. Guloksuz S, van Os J (2018) Need for evidence-based early intervention programmes: a public health perspective. Evid Based Ment Health 21(4):128. https://doi.org/10.1136/ebmen tal-2018-300030

5. van Os J, Guloksuz S (2017) A critique of the "ultra-high risk" and "transition" paradigm. World Psychiatry 16(2):200-206. https://doi.org/10.1002/wps.20423

6. Winslow CEA (1920) The untilled fields of public health. Science 51(1306):23-33. https://doi.org/10.1126/scien ce. 51.1306 .23

7. Bloom DE, Cafiero ET, Jane-Llopis E, Abrahams-Gessel S, Bloom LR, Fathima S, Fiegl AB, Mowafi M, Pandya A, Prettner K, Rosenberg L, Seligman B, Stein A, Weinstein C (2011) The global economic burden of non-communicable disease. World Economic Forum, Geneva

8. Patel V, Saxena S, Lund C, Thornicroft G, Baingana F, Bolton P, Chisholm D, Collins PY, Cooper JL, Eaton J, Herrman H, Herzallah MM, Huang Y, Jordans MJD, Kleinman A, Medina-Mora ME, Morgan E, Niaz U, Omigbodun O, Prince M, Rahman A, Saraceno B, Sarkar BK, De Silva M, Singh I, Stein DJ, Sunkel C, UnÜtzer J (2018) The Lancet Commission on global mental health and sustainable development. Lancet 392(10157):15531598. https://doi.org/10.1016/S0140-6736(18)31612-X

9. Mrazek PJ, Haggerty RJ (1994) Reducing risks for mental disorders: frontiers for preventive intervention research. National Academy Press, Washington

10. McGorry PD, Hickie IB (eds) (2019) Clinical staging in psychiatry: making diagnosis work for research and treatment. Cambridge University Press, Cambridge

11. Woods SW, Walsh BC, Saksa JR, McGlashan TH (2010) The case for including attenuated psychotic symptoms syndrome in DSM-5 as a psychosis risk syndrome. Schizophr Res 123(23):199-207. https://doi.org/10.1016/j.schres.2010.08.012 
12. Frances A (2013) Saving normal: an insider's revolt against outof-control psychiatric diagnosis, DSM-5, big pharma, and the medicalization of ordinary life. William Morrow, New York

13. Fusar-Poli P, Rocchetti M, Sardella A, Avila A, Brandizzi M, Caverzasi E, Politi P, Ruhrmann S, McGuire P (2015) Disorder, not just state of risk: meta-analysis of functioning and quality of life in people at high risk of psychosis. Br J Psychiatry 207(3):198-206. https://doi.org/10.1192/bjp.bp.114.157115

14. Yung AR, McGorry PD, McFarlane CA, Jackson HJ, Patton GC, Rakkar A (1996) Monitoring and care of young people at incipient risk of psychosis. Schizophr Bull 22(2):283-303. https://doi. org/10.1093/schbul/22.2.283

15. McGorry PD, Mei C, Hartmann J, Yung A, Nelson B (under review) Intervention strategies for ultra-high risk for psychosis: progress in delaying the onset and reducing the impact of firstepisode psychosis

16. Hutton P, Taylor PJ (2014) Cognitive behavioural therapy for psychosis prevention: a systematic review and meta-analysis. Psychol Med 44(3):449-468. https://doi.org/10.1017/s0033291713000354

17. Stafford MR, Jackson H, Mayo-Wilson E, Morrison AP, Kendall T (2013) Early interventions to prevent psychosis: systematic review and meta-analysis. BMJ 346:f185. https://doi.org/10.1136/bmj. f185

18. Ising HK, Kraan TC, Rietdijk J, Dragt S, Klaassen RMC, Boonstra $\mathrm{N}$, Nieman DH, Willebrands-Mendrik M, van den Berg DPG, Linszen DH, Wunderink L, Veling W, Smit F, van der Gaag M (2016) Four-year follow-up of cognitive behavioral therapy in persons at ultra-high risk for developing psychosis: the Dutch Early Detection Intervention Evaluation (EDIE-NL) Trial. Schizophr Bull 42(5):1243-1252. https://doi.org/10.1093/schbul/sbw018

19. van der Gaag M, Smit F, Bechdolf A, French P, Linszen DH, Yung AR, McGorry P, Cuijpers P (2013) Preventing a first episode of psychosis: meta-analysis of randomized controlled prevention trials of 12 month and longer-term follow-ups. Schizophr Res 149(1):56-62. https://doi.org/10.1016/j.schres.2013.07.004

20. Henry LP, Amminger GP, Harris MG, Yuen HP, Harrigan SM, Prosser AL, Schwartz OS, Farrelly SE, Herrman H, Jackson HJ, McGorry PD (2010) The EPPIC follow-up study of first-episode psychosis: longer-term clinical and functional outcome 7 years after index admission. J Clin Psychiatry 71(6):716-728. https:// doi.org/10.4088/JCP.08m04846yel

21. Fusar-Poli P, McGorry P, Kane JM (2017) Improving outcomes of first-episode psychosis: an overview. World Psychiatry 16(3):251265. https://doi.org/10.1002/wps.20446

22. Hegelstad WT, Larsen TK, Auestad B, Evensen J, Haahr U, Joa I, Johannesen JO, Langeveld J, Melle I, Opjordsmoen S, Rossberg JI, Rund BR, Simonsen E, Sundet K, Vaglum P, Friis STM (2012) Long-term follow-up of the TIPS early detection in psychosis study: effects on 10-year outcome. Am J Psychiatry 169(4):374380. https://doi.org/10.1176/appi.ajp.2011.11030459

23. McGorry PD, Hickie IB, Yung AR, Pantelis C, Jackson HJ (2006) Clinical staging of psychiatric disorders: a heuristic framework for choosing earlier, safer and more effective interventions. Aust N Z J Psychiatry 40(8):616-622. https://doi.org/10.111 1/j.1440-1614.2006.01860.x

24. Yung AR (2017) Treatment of people at ultra-high risk for psychosis. World Psychiatry 16(2):207-208. https://doi.org/10.1002/ wps. 20424

25. Malla A, Shah J, Lal S (2017) Advances and challenges in early intervention in psychosis. World Psychiatry 16(3):274-275. https ://doi.org/10.1002/wps.20453

26. McGorry PD, Mei C (2018) Ultra-high-risk paradigm: lessons learnt and new directions. Evid Based Ment Health 21(4):131133. https://doi.org/10.1136/ebmental-2018-300061

27. Pruessner M, Faridi K, Shah J, Rabinovitch M, Iyer S, Abadi S, Pawliuk N, Joober R, Malla AK (2017) The Clinic for
Assessment of Youth at Risk (CAYR): 10 years of service delivery and research targeting the prevention of psychosis in Montreal, Canada. Early Interv Psychiatry 11(2):177-184. https://doi. org/10.1111/eip. 12300

28. van der Gaag M, Schütz C, ten Napel A, Landa Y, Delespaul P, Bak M, Tschacher W, de Hert M (2013) Development of the Davos Assessment of Cognitive Biases Scale (DACOBS). Schizophr Res 144(1):63-71. https://doi.org/10.1016/j.schre s.2012.12.010

29. Yung AR, Cotter J, Wood SJ, McGorry P, Thompson AD, Nelson B, Lin A (2015) Childhood maltreatment and transition to psychotic disorder independently predict long-term functioning in young people at ultra-high risk for psychosis. Psychol Med 45(16):3453-3465. https://doi.org/10.1017/S003329171500135X

30. Sekar A, Bialas AR, de Rivera H, Davis A, Hammond TR, Kamitaki N, Tooley K, Presumey J, Baum M, Van Doren V, Genovese G, Rose SA, Handsaker RE, Schizophrenia Working Group of the Psychiatric Genomics Consortium, Daly MJ, Carroll MC, Stevens B, McCarroll SA (2016) Schizophrenia risk from complex variation of complement component 4. Nature 530:177-183. https:// doi.org/10.1038/nature16549

31. Kendler KS (2019) From many to one to many - the search for causes of psychiatric illness. JAMA Psychiatry 76(10):10851091. https://doi.org/10.1001/jamapsychiatry.2019.1200

32. Stein MB, Norman SB (2019) When does meta-analysis of a network not work? Fishing for answers. JAMA Psychiatry 76(9):885886. https://doi.org/10.1001/jamapsychiatry.2019.0902

33. Davies C, Cipriani A, Ioannidis JPA, Radua J, Stahl D, Provenzani U, McGuire P, Fusar-Poli P (2018) Lack of evidence to favor specific preventive interventions in psychosis: a network meta-analysis. World Psychiatry 17(2):196-209. https://doi.org/10.1002/ wps. 20526

34. Davies C, Radua J, Cipriani A, Stahl D, Provenzani U, McGuire P, Fusar-Poli P (2018) Efficacy and acceptability of interventions for attenuated positive psychotic symptoms in individuals at clinical high risk of psychosis: a network meta-analysis. Front Psychiatry 9:187. https://doi.org/10.3389/fpsyt.2018.00187

35. Naci H, Salcher-Konrad M, Dias S, Blum MR, Sahoo SA, Nunan D, Ioannidis JPA (2019) How does exercise treatment compare with antihypertensive medications? A network meta-analysis of 391 randomised controlled trials assessing exercise and medication effects on systolic blood pressure. Br J Sports Med 53(14):859-869. https://doi.org/10.1136/bjsports-2018-099921

36. Amick HR, Gartlehner G, Gaynes BN, Forneris C, Asher GN, Morgan LC, Coker-Schwimmer E, Boland E, Lux LJ, Gaylord S, Bann C, Pierl CB, Lohr KN (2015) Comparative benefits and harms of second generation antidepressants and cognitive behavioral therapies in initial treatment of major depressive disorder: systematic review and meta-analysis. BMJ 351:h6019. https://doi. org/10.1136/bmj.h6019

37. Preti A, Cella M (2010) Randomized-controlled trials in people at ultra high risk of psychosis: a review of treatment effectiveness. Schizophr Res 123(1):30-36. https://doi.org/10.1016/j.schre s.2010.07.026

38. McGorry PD, Nelson B, Markulev C, Yuen HP, Schafer MR, Mossaheb N, Schlogelhofer M, Smesny S, Hickie IB, Berger GE, Chen EY, de Haan L, Nieman DH, Nordentoft M, Riecher-Rossler A, Verma S, Thompson A, Yung AR, Amminger GP (2017) Effect of omega-3 polyunsaturated fatty acids in young people at ultrahigh risk for psychotic disorders: the NEURAPRO randomized clinical trial. JAMA Psychiatry 74(1):19-27. https://doi.org/10.1001/ jamapsychiatry.2016.2902

39. Nelson B, Amminger GP, Yuen HP, Markulev C, Lavoie S, Schäfer MR, Hartmann JA, Mossaheb N, Schlögelhofer M, Smesny S, Hickie IB, Berger G, Chen EYH, de Haan L, Nieman DH, Nordentoft M, Riecher-Rössler A, Verma S, Thompson A, 
Yung AR, McGorry PD (2018) NEURAPRO: a multi-centre RCT of omega-3 polyunsaturated fatty acids versus placebo in young people at ultra-high risk of psychotic disorders-medium-term follow-up and clinical course. NPJ Schizophr 4(1):11. https://doi. org/10.1038/s41537-018-0052-x

40. Herold KC, Bundy BN, Long SA, Bluestone JA, DiMeglio LA, Dufort MJ, Gitelman SE, Gottlieb PA, Krischer JP, Linsley PS, Marks JB, Moore W, Moran A, Rodriguez H, Russell WE, Schatz D, Skyler JS, Tsalikian E, Wherrett DK, Ziegler A-G, Greenbaum CJ (2019) An anti-CD3 antibody, teplizumab, in relatives at risk for type 1 diabetes. N Engl J Med 381(7):603-613. https://doi. org/10.1056/NEJMoa1902226

41. Ajnakina O, Morgan C, Gayer-Anderson C, Oduola S, Bourque F, Bramley S, Williamson J, MacCabe JH, Dazzan P, Murray RM, David AS (2017) Only a small proportion of patients with first episode psychosis come via prodromal services: a retrospective survey of a large UK mental health programme. BMC Psychiatry 17(1):308. https://doi.org/10.1186/s12888-017-1468-y

42. Fusar-Poli P, Rutigliano G, Stahl D, Davies C, Bonoldi I, Reilly T, McGuire P (2017) Development and validation of a clinically based risk calculator for the transdiagnostic prediction of psychosis. JAMA Psychiatry 74(5):493-500. https://doi.org/10.1001/ jamapsychiatry.2017.0284

43. Valmaggia LR, Byrne M, Day F, Broome MR, Johns L, Howes O, Power P, Badger S, Fusar-Poli P, McGuire PK (2015) Duration of untreated psychosis and need for admission in patients who engage with mental health services in the prodromal phase. Br J Psychiatry 207(2):130-134. https://doi.org/10.1192/bjp. bp.114.150623

44. Malla A, de Bonneville M, Shah J, Jordan G, Pruessner M, Faridi K, Rabinovitch M, Iyer SN, Joober R (2018) Outcome in patients converting to psychosis following a treated clinical high risk state. Early Interv Psychiatry 12(4):715-719. https://doi.org/10.1111/ eip. 12431

45. McGorry PD, Goldstone SD, Parker AG, Rickwood DJ, Hickie IB (2014) Cultures for mental health care of young people: an Australian blueprint for reform. Lancet Psychiatry 1(7):559-568. https://doi.org/10.1016/S2215-0366(14)00082-0

46. Malla A, Iyer S, Shah J, Joober R, Boksa P, Lal S, Fuhrer R, Andersson N, Abdel-Baki A, Hutt-MacLeod D, Beaton A, Reaume-Zimmer P, Chisholm-Nelson J, Rousseau C, Chandrasena R, Bourque J, Aubin D, Levasseur MA, Winkelmann I, Etter M, Kelland J, Tait C, Torrie J, Vallianatos H (2019) Canadian response to need for transformation of youth mental health services: ACCESS Open Minds (Esprits ouverts). Early Interv Psychiatry 13(3):697-706. https://doi.org/10.1111/eip.12772

47. Illback RJ, Bates T (2011) Transforming youth mental health services and supports in Ireland. Early Interv Psychiatry 5(s1):22-27. https://doi.org/10.1111/j.1751-7893.2010.00236.x

48. Rietdijk J, Klaassen R, Ising H, Dragt S, Nieman DH, van de Kamp J, Cuijpers P, Linszen D, van der Gaag M (2012) Detection of people at risk of developing a first psychosis: comparison of two recruitment strategies. Acta Psychiatr Scand 126(1):21-30. https://doi.org/10.1111/j.1600-0447.2012.01839.x

49. Nelson B, Amminger GP, Yuen HP, Wallis NJ, Kerr M, Dixon L, Carter C, Loewy R, Niendam TA, Shumway M, Morris S, Blasioli J, McGorry PD (2018) Staged Treatment in Early Psychosis: a sequential multiple assignment randomised trial of interventions for ultra high risk of psychosis patients. Early Interv Psychiatry 12(3):292-306. https://doi.org/10.1111/eip.12459

50. Hilferty F, Cassells R, Muir K, Duncan A, Christensen D, Mitrou F, Gao G, Mavisakalyan A, Hafekost K, Tarverdi Y, Nguyen H, Wingrove C, Katz I (2015) Is headspace making a difference to young people's lives? Final report of the independent evaluation of the headspace program. Social Policy Research Centre, UNSW, Sydney
51. Lincoln C, Harrigan S, McGorry PD (1998) Understanding the topography of the early psychosis pathways: an opportunity to reduce delays in treatment. Br J Psychiatry 172(Suppl 33):21-25. https://doi.org/10.1192/S0007125000297614

52. Lincoln C, McGorry PD (1999) Pathways to care in early psychosis: clinical and consumer perspectives. In: McGorry PD, Jackson HJ (eds) The recognition and management of early psychosis: a preventive approach. Cambridge University Press, Cambridge, pp $51-81$

53. Lincoln CV, McGorry P (1995) Who cares? Pathways to psychiatric care for young people experiencing a first episode of psychosis. Psychiatr Serv 46(11):1166-1171. https://doi.org/10.1176/ ps.46.11.1166

54. Yung AR, McGorry PD (1996) The prodromal phase of first-episode psychosis: past and current conceptualizations. Schizophr Bull 22(2):353-370. https://doi.org/10.1093/schbul/22.2.353

55. Fusar-Poli P, Bonoldi I, Yung AR, Borgwardt S, Kempton MJ, Valmaggia L, Barale F, Caverzasi E, McGuire P (2012) Predicting psychosis: meta-analysis of transition outcomes in individuals at high clinical risk. Arch Gen Psychiatry 69(3):220-229. https:// doi.org/10.1001/archgenpsychiatry.2011.1472

56. Yung AR, Nelson B (2013) The ultra-high risk concept—a review. Can J Psychiatry 58(1):5-12. https://doi.org/10.1177/0706743713 05800103

57. Addington J, Cornblatt BA, Cadenhead KS, Cannon TD, McGlashan TH, Perkins DO, Seidman LJ, Tsuang MT, Walker EF, Woods SW, Heinssen R (2011) At clinical high risk for psychosis: outcome for nonconverters. Am J Psychiatry 168(8):800-805. https://doi.org/10.1176/appi.ajp.2011.10081191

58. Lin A, Wood SJ, Nelson B, Beavan A, McGorry P, Yung AR (2015) Outcomes of nontransitioned cases in a sample at ultrahigh risk for psychosis. Am J Psychiatry 172(3):249-258. https:// doi.org/10.1176/appi.ajp.2014.13030418

59. Beck K, Andreou C, Studerus E, Heitz U, Ittig S, Leanza L, Riecher-Rossler A (2019) Clinical and functional long-term outcome of patients at clinical high risk (CHR) for psychosis without transition to psychosis: a systematic review. Schizophr Res 210:39-47. https://doi.org/10.1016/j.schres.2018.12.047

60. Shah JL, Crawford A, Mustafa SS, Iyer SN, Joober R, Malla AK (2017) Is the clinical high-risk state a valid concept? Retrospective examination in a first-episode psychosis sample. Psychiatr Serv 68(10):1046-1052. https://doi.org/10.1176/appi.ps.20160 0304

61. Lee TY, Lee J, Kim M, Choe E, Kwon JS (2018) Can we predict psychosis outside the clinical high-risk state? A systematic review of non-psychotic risk syndromes for mental disorders. Schizophr Bull 44(2):276-285. https://doi.org/10.1093/schbul/sbx173

62. Yung AR, Nelson B, Thompson A, Wood SJ (2010) The psychosis threshold in Ultra High Risk (prodromal) research: is it valid? Schizophr Res 120(1-3):1-6. https://doi.org/10.1016/j. schres.2010.03.014

63. Cropley VL, Lin A, Nelson B, Reniers RL, Yung AR, Bartholomeusz CF, Klauser P, Velakoulis D, McGorry P, Wood SJ, Pantelis C (2016) Baseline grey matter volume of non-transitioned "ultra high risk" for psychosis individuals with and without attenuated psychotic symptoms at long-term follow-up. Schizophr Res 173(3):152-158. https://doi.org/10.1016/j.schres.2015.05.014

64. Nelson B, Yuen HP, Wood SJ, Lin A, Spiliotacopoulos D, Bruxner A, Broussard C, Simmons M, Foley DL, Brewer WJ, Francey SM, Amminger GP, Thompson A, McGorry PD, Yung AR (2013) Long-term follow-up of a group at ultra high risk ("prodromal") for psychosis: the PACE 400 study. JAMA Psychiatry 70(8):793802. https://doi.org/10.1001/jamapsychiatry.2013.1270

65. Wigman JT, van Nierop M, Vollebergh WA, Lieb R, BeesdoBaum K, Wittchen HU, van Os J (2012) Evidence that psychotic symptoms are prevalent in disorders of anxiety and depression, 
impacting on illness onset, risk, and severity-implications for diagnosis and ultra-high risk research. Schizophr Bull 38(2):247257. https://doi.org/10.1093/schbul/sbr196

66. Lim J, Rekhi G, Rapisarda A, Lam M, Kraus M, Keefe R, Lee J (2015) Impact of psychiatric comorbidity in individuals at ultra high risk of psychosis - findings from the Longitudinal Youth at Risk Study (LYRIKS). Schizophr Res 164(1-3):8-14. https://doi. org/10.1016/j.schres.2015.03.007

67. Hartmann JA, Nelson B, Spooner R, Paul Amminger G, Chanen A, Davey CG, McHugh M, Ratheesh A, Treen D, Yuen HP, McGorry PD (2019) Broad clinical high-risk mental state (CHARMS): methodology of a cohort study validating criteria for pluripotent risk. Early Interv Psychiatry 13(3):379-386. https ://doi.org/10.1111/eip.12483

68. Iorfino F, Scott EM, Carpenter JS, Cross SP, Hermens DF, Killedar M, Nichles A, Zmicerevska N, White D, Guastella AJ, Scott J, McGorry PD, Hickie IB (2019) Clinical stage transitions in persons aged 12 to 25 years presenting to early intervention mental health services with anxiety, mood, and psychotic disorders. JAMA Psychiatry 76(11):1167-1175. https://doi.org/10.1001/ jamapsychiatry.2019.2360

69. Hickie IB, Scott EM, Hermens DF, Naismith SL, Guastella AJ, Kaur M, Sidis A, Whitwell B, Glozier N, Davenport T, Pantelis C, Wood SJ, McGorry PD (2013) Applying clinical staging to young people who present for mental health care. Early Interv Psychiatry 7(1):31-43. https://doi.org/10.1111/j.1751-7893.2012.00366.x

70. McGorry PD (2007) Issues for DSM-V: clinical staging: a heuristic pathway to valid nosology and safer, more effective treatment in psychiatry. Am J Psychiatry 164(6):859-860. https://doi. org/10.1176/ajp.2007.164.6.859

71. Purcell R, Jorm AF, Hickie IB, Yung AR, Pantelis C, Amminger GP, Glozier N, Killackey E, Phillips LJ, Wood SJ, Harrigan S, Mackinnon A, Scott E, Hermens DF, Guastella AJ, Kenyon A, Mundy L, Nichles A, Scaffidi A, Spiliotacopoulos D, Taylor L, Tong JP, Wiltink S, Zmicerevska N, McGorry PD (2015) Demographic and clinical characteristics of young people seeking help at youth mental health services: baseline findings of the Transitions Study. Early Interv Psychiatry 9(6):487-497. https://doi. org/10.1111/eip.12133

72. Hyman SE (2010) The diagnosis of mental disorders: the problem of reification. Annu Rev Clin Psychol 6:155-179. https://doi. org/10.1146/annurev.clinpsy.3.022806.091532

73. Cuthbert BN, Insel TR (2010) Toward new approaches to psychotic disorders: the NIMH Research Domain Criteria project.
Schizophr Bull 36(6):1061-1062. https://doi.org/10.1093/schbu $1 / \mathrm{sbq} 108$

74. Cuthbert BN, Insel TR (2013) Toward the future of psychiatric diagnosis: the seven pillars of RDoC. BMC Med 11:126. https:// doi.org/10.1186/1741-7015-11-126

75. Kotov R, Krueger RF, Watson D (2018) A paradigm shift in psychiatric classification: the Hierarchical Taxonomy of Psychopathology (HiTOP). World Psychiatry 17(1):24-25. https://doi. org/10.1002/wps.20478

76. Cuthbert BN (2014) The RDoC framework: facilitating transition from ICD/DSM to dimensional approaches that integrate neuroscience and psychopathology. World Psychiatry 13(1):28-35. https://doi.org/10.1002/wps.20087

77. Kotov R, Krueger RF, Watson D, Achenbach TM, Althoff RR, Bagby RM, Brown TA, Carpenter WT, Caspi A, Clark LA, Eaton NR, Forbes MK, Forbush KT, Goldberg D, Hasin D, Hyman SE, Ivanova MY, Lynam DR, Markon K, Miller JD, Moffitt TE, Morey LC, Mullins-Sweatt SN, Ormel J, Patrick CJ, Regier DA, Rescorla L, Ruggero CJ, Samuel DB, Sellbom M, Simms LJ, Skodol AE, Slade T, South SC, Tackett JL, Waldman ID, Waszczuk MA, Widiger TA, Wright AGC, Zimmerman M (2017) The Hierarchical Taxonomy of Psychopathology (HiTOP): a dimensional alternative to traditional nosologies. J Abnorm Psychol 26(4):454-477. https://doi.org/10.1037/abn0000258

78. Tyrer P (2018) Dimensions fit the data, but can clinicians fit the dimensions? World Psychiatry 17(3):295-296. https://doi. org/10.1002/wps.20559

79. Kotov R, Jonas KG, Carpenter WT, Dretsch MN, Eaton NR, Forbes MK, Forbush KT, Hobbs K, Reininghaus U, Slade T, South SC, Sunderland M, Waszczuk MA, Widiger TA, Wright Aidan GC, Zald DH, Krueger RF, Watson D, Workgroup HiTOP Utility (2020) Validity and utility of Hierarchical Taxonomy of Psychopathology (HiTOP): I. Psychosis superspectrum. World Psychiatry 19(2):151-172. https://doi.org/10.1002/wps.20730

80. Shah JL (2019) Bringing clinical staging to youth mental health: from concept to operationalization (and back again). JAMA Psychiatry 76(11):1121-1123. https://doi.org/10.1001/jamapsychi atry.2019.2003

81. McGorry P, Trethowan J, Rickwood D (2019) Creating headspace for integrated youth mental health care. World Psychiatry 18(2):140-141. https://doi.org/10.1002/wps.20619 